\title{
REVISTA \\ PERDE PARA TV
}

\author{
Os veículos de comunicação têm especialidades próprias, linguagens e \\ abordagens diferenciadas das temáticas; descuidar de tais \\ aspectos frustra o leitor e provoca dúvidas quanto à validade de cada um
}

A revista Istoé de 17 de maio traz como reportagem de capa "Aventura no Ártico: o empresário brasileiro Camille Kachani vive a emoção de percorrer as trilhas geladas da Groenlândia”.

O Globo Repórter de 19 de maio é dedicado à aventura de um repórter que convive com os esquimós da Groenlândia no seu cotidiano. Participa com eles de uma caçada, aprende a sobreviver num frio de 20 graus negativos, viajando em trenós puxados por cães, armando barracas, transformando gelo em água para beber e preparar alimentos.

O Globo Repórter foi levado ao ar na noite de sexta-feira e a revista foi distribuída aos assinantes no final da semana, como de hábito. A "coincidência" não teria qualquer problema para o leitor. Pelo contrário, tendo assistido ao Globo Repórter, a recorrência do tema no veículo impresso passa a significar a possibilidade de dispor do registro das informações para usos diversos, inclusive didático, frente à impossibilidade de reter as imagens sucessivas e o rápido e vo-

\section{A AUTORA \\ Maria Lourdes Motter \\ Professora Doutora do Departamento de Comuni- caçōes e Artes da ECA-USP. Especialista em Linguagem Verbal nos Meios de Comunicação.}

látil texto oral da TV, já que a gravação em vídeo exige um mínimo de programação por parte do telespectador que, em geral, descobre uma matéria interessante acionando distraidamente o controle remoto.

Nesse aspecto, a revista, como o jornal, goza de mais estabilidade graças à linguagem escrita que lhe atribui o caráter de registro, de documento disponível para avivar a lembrança, ilustrar, abonar citações. Enfim ela permite a reprodução, permanece, dura.

A TV dispõe de muitas outras vantagens. É mais atraente, mais leve e menos compromissada enquanto texto pois se apóia no movimento dos referentes, que são as imagens que o documentam. Essas epecificidades percebidas pelo telespectador-leitor comum servem até de pretexto para matérias que se reduzem, enquanto conteúdo infomativo, a pouco mais do que contém o próprio título. Esse não é o caso do Globo Repórter de que estamos tratando.

\section{TRATAMENTOS DIFERENCIADOS}

Os meios de comunicação cumprem funções diferentes. Convivem em harmonia atentendendo às necessidades de entrenimento, informação, análise, reflexão sobre os mesmos ou diferentes assuntos. Com freqüência, busca-se ampliar o conhecimento sobre um tema recorrendo a todos eles. É assim que o mesmo noticiário da TV será li- 
do no jornal do dia seguinte, ou procurado nos telejornais de outras emissoras, no rádio, em diversos jornais impressos e, também, nas revistas semanais.

Cada emissora de TV, cada órgão de imprensa e, por sua vez, cada revista pode manifestar um enfoque diferente dando ênfase ao que foi desconsiderado pelos outros meios, acrescentar detalhes, adotar um ponto de vista particular, ampliando as possibilidades de interpretação do acontecimento.

Se a TV dispõe de recursos como a linguagem oral e a imagem com cor e movimento, a mensagem resultante tenderá a ser mais agradável em razão da combinação harmoniosa daqueles recursos. Agilidade e rapidez garantem o ritmo que prende a atenção do leitor. Esse ritmo ideal não considera, porém, a capacidade de apreensão do leitor. Ela é variável, podendo ser até nula ou aproximar-se disso em razão do tema e do caráter técnico do tratamento dado a ele.

No jornal, via de regra, apressada é a sua produção: entre a pauta, o trabalho do repórter, o número de linhas a serem escritas e o fechamento e distribuição do jornal nas primeiras horas da manhã, o tempo é curto. A notícia tem que sair no dia: ela envelhece em poucas horas. O tempo de leitura, pelo contrário, é regulado pelo leitor: vai de um olhar, uma leitura rápida a um guardar o texto para um momento de maior recolhimento e concentração. O texto escrito goza da permanência, pode ser lido na hora e resgatado para novas leituras com diferentes níveis de atenção.

$\mathrm{O}$ que se volatiliza na TV permanece no jornal. É informação disponível podendo servir de prova, de documento. A falta das imagens em movimento é suprida pelo detalhamento no texto escrito, mais exigente quanto aos dados essenciais porque a palavra escrita não tem os apoios da linguagem oral. Em geral, as notícias impressas têm por característica o aprofundamento, a investigação, o maior número de dados, de depoimentos, o confronto de versões.

A revista semanal, além do que já se apontou para o jornal, tem ainda a função analítica e reflexiva. O maior tempo de produção - e para pesquisa - , ou o distanciamento temporal em relação ao acontecimento fazem dela um veículo voltado para o rigor crítico, sobretudo por ter a sua disposição todos os textos escritos ou orais dos demais veículos para elaborar a síntese analítica contrapondo visões, trazendo novos elementos capazes de projetar luz sobre as causas e as conseqüências próximas ou remotas que podem contextualizar mais amplamente o assunto, adensar seu conhecimento e inseri-lo no processo histórico.

Não há dúvida quanto às diferenças. Por essa razão os assuntos podem repetir-se e repetem-se nos vários veículos.

\section{INFORMAÇÕES, BELEZA E BOM HUMOR}

O programa Globo Repórter não só nos mostrou um pouco da vida cotidiana do esquimó, como eliminou uma série de idéias erradas ou desatualizadas sobre a cultura desse povo. Por exemplo, eles não constituem um único grupo, o que implica pensar diferenças em função de habitarem regiões frias diversas. Não são os anões que a nossa sociedade nos ensinou a imaginar, embora não sejam altos. Não oferecem a mulher para dormir com o visitante como ensina o folclore, presente até nas salas de aula da universidade para ilustrar diferenças culturais. Mas não é só. Onde foram parar os "iglus", aquelas casinhas de gelo arredondadas? Os esquimós da Groenlândia habitam casas de madeira, dispõem de iluminação nas ruas e nas casas, têm aparelhos de TV, vídeo, rádio e dispõem de alimentos industrializados. As crianças estudam em boas escolas, jogam futebol e conhecem o nome de jogadores da seleção brasileira. 
Ao lado disso, tentam manter tradições, como a caça, e demonstram a capacidade adaptativa do homem ao meio ambiente quando ingerem o fígado do animal recém morto para atender a sua necessidade de vitamina C, numa região onde não se pode depender da terra e dos nutrientes fornecidos pelos vegetais (verduras, legumes, frutas, por exemplo).

Com imagens bonitas e senso de humor do repórter, a promessa de aventura se cumpriu. Mas o programa foi além mostrando a vida possível em condições para nós tão adversas enquanto o homem sobrevive em harmonia com uma natureza dura e inóspita. Ademais, acrecenta-se que os esquimós que habitavam a região norte dos Estados Unidos se descaracterizaram enquanto grupo cultural e, como os nossos índios "aculturados", se dispersaram sem ocupação ou rumo certo e se entregam ao alcoolismo.

Perderam seu enraizamento com a dissolução da cultura. Sem identidade, perambulam à margem de outros grupos, tendendo a desaparecer completamente.

Um programa superior à média: pela oportunidade do tema e seu tratamento, dentro dos limites do veículo. Ficaram muitas perguntas. O tema merece uma retomada. Mas, sempre é possível a complementação por outro veículo, já que o aprofundamento não é a marca registrada da televisão.

É o que se esperou da revista Istoé e ela, não se sabe por que, não preservou sua diferença enquanto veículo impresso. Destacou o aspecto de aventura trazendo para suas páginas o depoimento de um empresário que visitou o pólo para fotografar a quase inacessível e rara paisagem para nós habitantes dos trópicos. A beleza e o exotismo, além do talento do fotógrafo, povoam os espaços da reportagem e o texto, muito aquém do esperado (a matéria deu a capa da revista) fala mais da paisagem e da aventura do que do homem esquimó e de sua cul- tura. Além de exibir belas fotos, a matéria não acrescenta ao Globo Repórter.

\section{SUPERFICIALIDADE}

Naturalmente, estamos assumindo um ponto de vista de quem entende que a convivência dos meios de comunicação é boa e saudável enquanto se preservam as identidades, as peculiaridades e um modo específico de ser de cada um. O problema se mostra quando se anulam as diferenças de tratamento que cada tema deve merecer de cada veículo. Enfim, quando a revista reproduz o mesmo ou menos que a TV - em termos de informação suas fotos, por mais eloqüentes que possam ser, não têm como competir com a fluência da fala e as imagens coloridas se sucedendo no movimento da câmera que varre o espaço e capta as pessoas no agir em cena.

É quando a revista frustra o leitor e perde a oportunidade de tratar, como é de sua índole, um raro e oportuno tema, de forma analítica, reflexiva e aprofundada. $\mathbf{A}$ superficialidade anula a diferença, pois tira a especificidade do veículo. É essa especificidade que assegura a condição de leitor da revista ao leitor do jornal, de outras revistas e do telespectador reunidos em uma só pessoa ao mesmo tempo.

Finalmente, há de se considerar que órgãos com iguais funções - no caso, duas revistas, por exemplo - só podem demarcar um espaço e garantir a fidelidade do seguimento consumidor, a partir da diferença que marca sua individualidade. Os prêmios consolatórios distribuídos por jornais e revistas aos leitores podem representar pequenas alegrias e até agradáveis surpresas como foi, por exemplo, o encarte em fascículos, na revista Istoé, da obra de Gabriel Garcia Marques O general em seu labirinto, mas não suprem o descuido com a qualidade da revista. A cerrada disputa no oferecimento de brindes só se torna saudável e influi na opção do leitor 


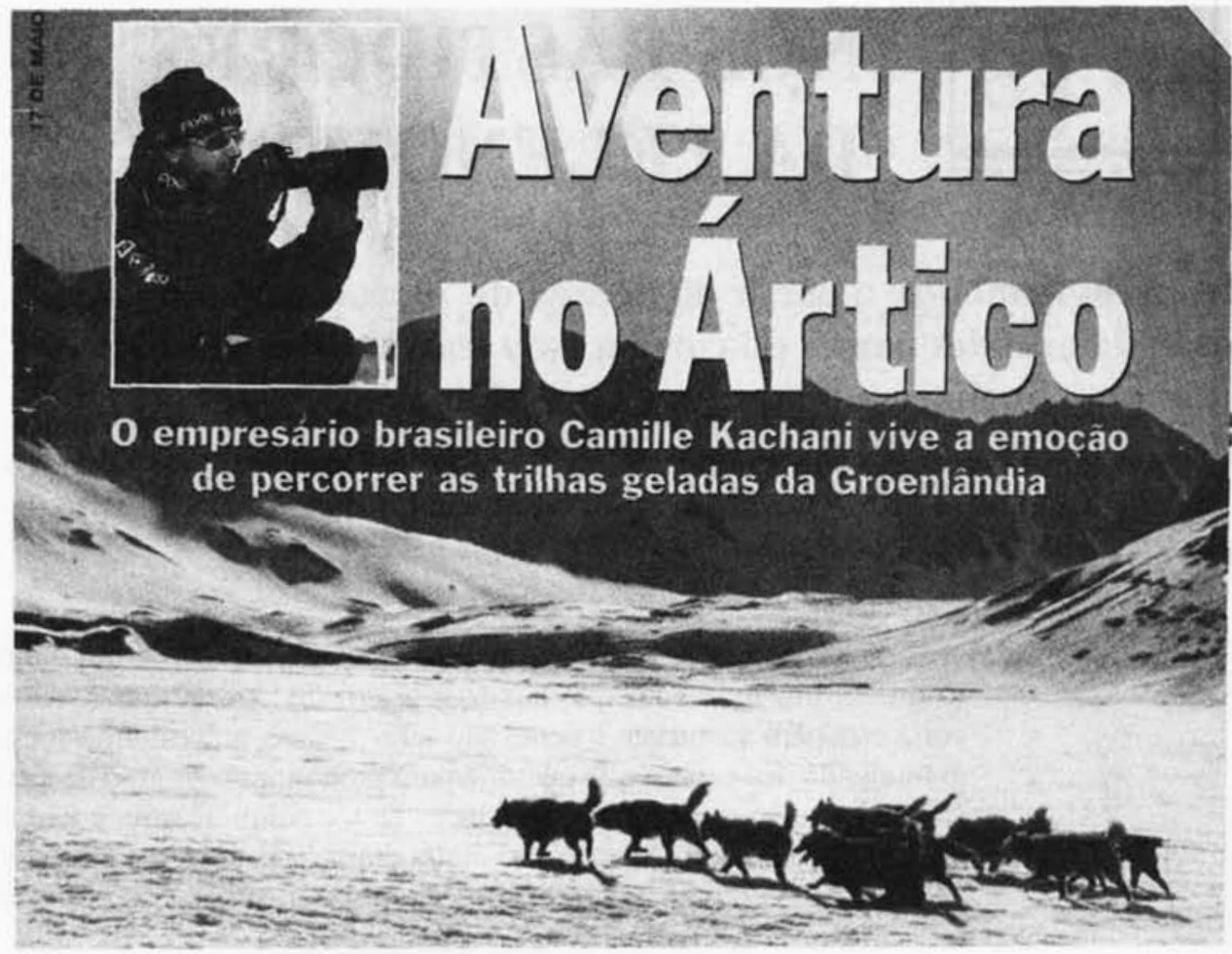

A matéria Aventura no Ártico foi capa da revista Istoé de 17/05/95.

quando a qualidade não está em questão. Poucos são os leitores - se é que existem que decidem em função de elementos completamente externos e acessórios, ou seja, por interesses que nada têm a ver com os veícu- los enquanto produtos culturais em si mesmos. Nesse caso, os prêmios funcionam e as boas idéias podem até definir a disputa. Mas, convém insistir, parafraseando o poeta: desculpem, mas a qualidade é fundamental. 